\title{
Van eerste overheid naar eerst de burger, maar hoe?*
}

\author{
Yvonne Kleistra \& Guido Walraven
}

\begin{abstract}
Het eerste adviesrapport van de Denktank VNG richt zich op de vraag hoe lokale overheden hun eigen prestaties kunnen versterken ten aanzien van de huidige trend van maatschappelijke initiatieven waarbij burgers zichzelf organiseren om samen problemen in straat, buurt of wijk aan te pakken. In dit artikel worden kanttekeningen geplaatst bij het in het rapport gekozen burgerperspectief, de kritiekloze houding ten aanzien van de schaduwkanten van de participatiesamenleving, de weinig diepgaande methode van onderzoek, en in het bijzonder het advies aan gemeenten om op grote schaal te gaan experimenteren en improviseren zonder verdere uitwerking van de centrale vraag 'hoe te handelen'. De analyse mondt uit in de conclusie dat de Denktank met het doen van suggesties alleen de lat te laag legt, en juist dit soort lastige vragen empirisch dient te verkennen en met wetenschappelijke inzichten dient te verbinden, wil deze in de nabije toekomst tot een gezaghebbende kennisinstantie voor lokale overheden kunnen uitgroeien.
\end{abstract}

\section{Inleiding}

In november 2013 is het eerste rapport verschenen van de Denktank Vereniging van Nederlandse Gemeenten. De Denktank (met hoofdletter!), die onder leiding van Rob van Gijzel staat, werd in 2012 opgericht om gemeenten te adviseren over thema's die op de langere termijn voor gemeenten relevant lijken. 'Ze moet in haar denken over de toekomst dus voorop lopen', zo lezen we in de preambule (Denktank VNG, 2013, p. 10). Dat schept hoge verwachtingen, mede omdat de activiteiten van de Denktank zich als eerste hebben gericht op de manier waarop gemeenten hun eigen optreden kunnen verbeteren en versterken ten aanzien van de huidige trend van maatschappelijke initiatieven waarbij burgers zichzelf organiseren om samen problemen in straat, buurt of wijk aan te pakken. Dat is een thema waarover in goed een jaar tijd niet alleen lijvige adviesrapporten zijn verschenen van professionele denktanks als de WRR (juni 2012), Rob (november 2012) en RMO (juli 2013), maar tevens - en mede in antwoord op de niet aflatende stroom van adviezen op dit terrein - een heuse kabinetsnota (juli 2013) als politiek-bestuurlijke reactie op de beleidstransitie naar meer doe-democratie.

De Denktank bestaat met uitzondering van een enkele bestuurskundehoogleraar volledig uit gemeentelijke bestuurders. De inzichten van een groep van practitioners over een onderwerp als de participatiesamenleving waar zich al

* De auteurs bedanken graag de referenten voor hun nuttige aanvullingen. 
sinds de jaren zeventig vele democratietheoretici over hebben gebogen, zou dan wel eens heel verfrissend kunnen zijn. Maar helaas heeft de VNG-denktank met dit eerste rapport zijn ambitie om als gemeentelijke adviesinstantie voorop te lopen nog niet waar weten te maken. Dat komt vooral doordat het VNG-advies voor de leden zelf nog te veel een ontdekkingstocht is geworden. In het rapport wordt met grove penseelstreken de ontwikkeling geschetst van drie golven van maatschappelijke initiatieven sinds de middeleeuwen en de omstandigheden waaruit het ontstaan van deze golven kan worden verklaard. De Denktank is vervolgens in het afgelopen jaar het hele land doorgereisd om burgerinitiatieven te bezoeken en zodoende de nodige ervaringen op te doen en inzichten te ontwikkelingen ten aanzien van de laatste golf. Met deze werkwijze is hij niet verder gekomen dan waar andere adviesinstanties zijn bleven steken, namelijk de constatering dat er (1) 'in Nederland momenteel een groeiende verzameling van actieve, zelfbewuste, hoog opgeleide, ondernemende, kritische, ambitieuze, ongeduldige, zelfredzame en eigenwijze burgers is die het vormgeven van de publieke zaak zelf ter hand nemen en daarbij steeds minder met de gevestigde instituties op hebben', (2) dat gemeenten als het over burgerinitiatieven gaat een aangeboren neiging lijken te bezitten om de hakken in het zand te zetten, en (3) dat het zaak is dat gemeenten een andere rol gaan aannemen ten aanzien van deze maatschappelijke initiatieven, omdat het hier niet gaat om een tijdelijk fenomeen, maar om een langere termijn tendens. De voornaamste aanbevelingen die op grond van deze vaststellingen worden gedaan, luiden dat gemeenten bij het zoeken naar manieren om met deze initiatieven om te gaan op grote schaal moeten gaan experimenteren met nieuwe werkwijzen, en dat raadsleden, collegeleden en ambtenaren het vermogen tot improviseren niet alleen als een noodoplossing, maar als een kernkwaliteit van hun eigen functioneren moeten gaan opvatten. Geen speciale afdeling voor maatschappelijke initiatieven oprichten dus, maar in de lijn oppakken, want zo stelt de Denktank: 'Dit vermogen moet tot in de haarvaten van de bestuurlijke organisatie doordringen' (Denktank VNG, 2013, p. 69). Maar hoe dat improviseren en experimenteren ook echt handen en voeten kan krijgen, laat de Denktank helaas in het midden.

We willen bij de bespreking van het rapport kanttekeningen plaatsen bij:

1 het automatisme waarmee in het rapport opnieuw voor het perspectief van de burger gekozen is;

2 de vanzelfsprekendheid waarmee de Denktank de maatschappelijke initiatieven naar voren schuift als een sociale oplossing voor het dichten van de kloof tussen burger en politiek;

3 en het gemak waarmee het rapport uitmondt in de aanbeveling dat maatschappelijke initiatieven vaker aanleiding voor experimenten zouden moeten zijn, waarbij de gemeenten hun vermogen tot improviseren versterken.

\section{Het perspectief van de burger}

In het rapport is als vanzelfsprekend het perspectief van de burger gekozen. 'De burger centraal' zegt de Denktank, en zo luidt ook de titel van het advies 'Van 
eerste overheid naar eerst de burger'. Dat is natuurlijk een heel mooi uitgangspunt van een gemeentelijke adviesinstantie. En het is ook een veilig uitgangspunt. Maar het is nog maar de vraag of het doen en laten van die burger bij het ontplooien van maatschappelijke initiatieven ook in het rapport zelf de meeste aandacht had moet krijgen. Het is vooral de bedoeling van de Denktank geweest om gemeenten met dit rapport een aantal suggesties te kunnen doen over de manier waarop die hun eigen optreden kunnen verbeteren. Het is dan zeker nodig, zoals de Denktank stelt, om de maatschappelijke initiatieven vanuit hun kern te beschrijven en begrijpen, wil men die suggesties kunnen doen. Zo'n beschrijving begint inderdaad bij de initiatieven en hun volgers. Maar vroeg of laat - en dat geeft de Denktank ook zelf aan - komt de gemeentelijke overheid in beeld, omdat maatschappelijke initiatieven op enig moment hulp van die overheid nodig hebben. Het is dan eveneens nodig om het doen en laten van gemeenten richting maatschappelijke initiatieven vanuit hun kern te beschrijven en te begrijpen, om voor die groep tot bruikbare handreikingen te komen.

Dat laatste is helaas nu niet gebeurd. De Denktank heeft zich hier beperkt tot een wel heel summiere inventarisatie van klassieke weerstandsreacties ('Dit wil de wethouder niet', 'Dit past niet in het collegebeleid', 'Wij hebben op het moment andere prioriteiten', 'Dit wil de raad niet', 'Dit schept een precedent en dan is het hek van de dam', 'Burgers zijn niet in staat om dergelijke complexe afwegingen te maken', 'Daar gaan burgers niet over' en 'Het politieke primaat ligt bij de raad') van de drie gemeentelijke gremia richting maatschappelijk initiatief. Daarvan konden we al kennisnemen via de roze boxen in het WRR-rapport (2012a). Het is dan een gemiste kans om dan niet automatisch te willen kiezen voor diepgaande analyse van die gemeentelijke weerstand. Als de insteek van de Denktank inderdaad 'de burger centraal' is, en in de literatuur het perspectief van de burger domineert, dan zou het toch des te relevanter voor een gemeentelijke denktank zijn om nu eens niet te blijven steken in kretologie, maar eens grondig te gaan bekijken wat er binnen gemeentelijke muren nu precies wel of niet gebeurt als het om maatschappelijke initiatieven gaat. Alleen op die manier kunnen we meer inzicht krijgen in de vraag waarom die weerstand zo hardnekkig is en hoe gemeenten in de toekomst de voorwaarden zouden kunnen scheppen om de kloof tussen 'willen' en 'kunnen' te slechten.

\section{Maatschappelijk initiatief als panacee voor het politieke participatieprobleem}

Een tweede punt dat zeker aandacht verdient - niet in de laatste plaats omdat het een van de weinige momenten is waarop het rapport werkelijk aanhaakt bij de tegenstellingen die er onder democratietheoretici rondom het thema van de participatiesamenleving leven - is de wijze waarop de Denktank de maatschappelijke initiatieven naar voren schuift als een soort van bindmiddel voor het dichten van de kloof tussen burger en politiek. Daartoe wordt die kloof nu wel heel selectief neergezet als een probleem van afnemend vertrouwen in het Nederlandse politieke stelsel van coalitievorming, waarin mondige, eigenzinnige en initiatiefrijke 
burgers hun visie op de publieke zaak steeds minder herkennen in bestuurlijk handelen, en in toenemende mate moeite hebben met de manier waarop het stelsel van Thorbecke functioneert.

Wanneer we de discussie over de kloof in de afgelopen twintig jaar nog eens terughalen, dan was dat toch vooral een discussie die haar oorsprong vond in het feit dat het juist de groepen van niet zo mondige, eigenzinnige en initiatiefrijke burgers waren, die zich buitengesloten voelden van de politiek. Daarbij werd het toentertijd vooral als problematisch ervaren dat de Tweede Kamer in demografisch opzicht (leeftijd, geslacht, opleiding, etnische achtergrond) een allesbehalve representatieve afspiegeling vormde van het kiezersvolk dat zij meende te vertegenwoordigen. Hierdoor zouden de ideeën van een grote delen van de Nederlandse bevolking - niet alleen laagopgeleiden, hoewel het debat zich gaandeweg op deze groep toespitste, maar ook vrouwen, allochtonen en jongeren - niet echt worden gehoord. In het rapport van de Denktank wordt daar met geen woord over gerept. In plaats daarvan wordt het participatiedebat afgedaan als een weinig productieve discussie tussen etatisten en populisten, waarna het maatschappelijk initiatief wordt opgediend als een bijzonder relevant alternatief (Denktank VNG, 2013, p. 60).

Door het probleem van politieke participatie in termen van over- en ondervertegenwoordiging buiten de deur te houden wordt de lezer tevens het zicht ontnomen van innerlijke tegenstrijdigheden die het advies op dit punt in zich draagt. Het heeft er immers alle schijn van - en daar levert de Denktank ook zelf het nodige bewijsmateriaal voor - dat het politieke participatieprobleem wel eens niet zo snel zal worden opgelost via het spoor van het maatschappelijke initiatief. Evelien Tonkens stelde in 2010 in een BSK-bijdrage over de kwaliteit van burgerparticipatie in de stad dat we uit eerder onderzoek weten dat er in de praktijk veel belemmeringen zijn voor participatie in burgerinitiatieven; "je moet behoorlijk zelfbewust, reflexief en bureaucratisch competent zijn en over een (georganiseerd) sociaal netwerk beschikken, waardoor het vaak steeds dezelfde mensen zijn die participeren', aldus Tonkens (2010, pp. 36-37). De Denktank stelt op basis van veldonderzoek vast dat het niet alleen mondige en eigenwijze, maar vooral ook hoogopgeleide burgers zijn die zich inzetten voor maatschappelijke initiatieven. Dat zijn dus vooral de groepen die traditioneel binnen het oude bestel al behoorlijk wat ruimte kregen om hun denkbeelden en voorkeuren met betrekking tot de publieke zaak te realiseren.

Wat dit betreft is het van belang op deze plaats stil te staan bij de resultaten van een kwantitatief onderzoek naar burgerinitiatieven in Overijssel, dat evenals het denktankrapport in november 2013 het daglicht zag. Daarin komen Bas Denters, Judith Bakker, Mirjan Oude Vrielink en Marcel Boogers tot de conclusie dat er van een (sterke) oververtegenwoordiging van hoger opgeleiden in Overijsselse burgerinitiatieven geen sprake is (Denters et al., 2013, p. 11). Maar tegelijkertijd bevestigen zij het al eerder door Tonkens geschetste beeld dat lang niet alle burgers actief zijn: slechts 16 procent van de volwassen burgers in Overijssel is in de afgelopen twee jaar betrokken geweest bij één of meerdere burgerinitiatieven (ibid., p. 10). Bovendien stellen zij vast - en dit is eveneens een belangrijk gegeven in het licht van de oude kloofdiscussie - dat het percentage groepen met een 
mannelijke oververtegenwoordiging duidelijk groter is dan het relatieve aantal kerngroepen waarin vrouwen de overhand hebben, en dat jongeren daarin systematisch ondervertegenwoordigd zijn (ibid., p. 11).

Het is niet onwaarschijnlijk dat er significante verschillen zijn tussen deelname aan burgerinitiatieven in de regionale stedelijke samenlevingen en zijn grootstedelijke varianten die de hoofdmoot uitmaken van het databestand van de Denktank. Bas Denters, Judith Bakker en Pieter-Jan Klok kwamen op basis van een (landelijke) vergelijkende studie waarin burgers die actief betrokken zijn bij burgerinitiatieven werden vergeleken met minder actieve burgers, eveneens tot de conclusie dat bevoorrechte sociale groepen (bijvoorbeeld hoog inkomen en goed opgeleide mensen) oververtegenwoordigd zijn onder de meer actieve burgers en dat deze bias geldt voor zowel individuele als collectieve buurtinitiatieven (Denters, Bakker, \& Klok, 2011). En de eigen onderzoekservaringen in de grootstedelijke regio Rotterdam in aanmerking nemend valt tevens op dat in geen van de onderzoeken wordt gerept over de deelname van allochtonen, een groep die in de moderne geürbaniseerde samenleving waar de Denktank over spreekt niet alleen een steeds groter aandeel van de bevolking voor zijn rekening is gaan nemen, maar politiek gezien nog steeds ondervertegenwoordigd is.

Kortom, er zijn vele redenen om warm te lopen voor het fenomeen van het burgerinitiatief, zoals de Denktank dat overduidelijk doet. Maar het is op z'n minst onduidelijk of het dichten van de kloof tussen burger en politiek daar op de korte termijn toe zal gaan behoren.

\section{Voortbouwen op eerdere inzichten en onderzoek}

Wat verder opvalt in het rapport en de aanbevelingen, is dat er weinig tot geen oog is voor de schaduwzijden van het burgerinitiatief en dat de beleidscontroverses die in de discussies over de nieuwe vormen van burgerparticipatie telkens weer oplaaien volledig worden genegeerd. Dit wordt in de hand gewerkt door de keuze om de participatiesamenleving op te vatten als een neutrale duiding voor 'tendensen die we vandaag de dag al overal om ons heen waarnemen' en niet ook als 'een bepaald ideaal, de overtuiging dat het goed zou zijn als individuele burgers hun lot in eigen hand nemen en op die manier een actieve bijdrage leveren' en 'de wens van sommigen om sterk op de overheidsuitgaven te bezuinigen' (Denktank VNG, 2013, p. 15). Zo heeft bijvoorbeeld Justus Uitermark (2014) nog recentelijk in zijn oratie de nodige aandacht gevraagd voor de potentiële risico's die kleven aan een al te innig omarmen van het principe van zelforganisatie onder de noemer 'burgerkracht'. Hij wijst er onder andere op dat burgerinitiatieven zowel ingaan op publieke waarden als op eigen wensen van de deelnemers en dat het aan de gemeentelijke overheid is om de wensen van alle burgers in het oog te houden. Ook het SCP (2012) gaat daar uitgebreid op in, met het oog op het nieuwe besturingsmodel dat zich aftekent en waar kritische kanttekeningen bij worden geplaatst. Juist voor een bestuurlijke denktank zijn die dilemma's van belang. 
Daarmee raken we aan het meest opmerkelijke aspect van het rapport: daarin is geen aansluiting is gezocht bij de talrijke concrete handreikingen en inzichten uit de rapporten van de WRR, Rob en RMO. Deze rapporten worden wel benoemd, maar gebruikt worden ze niet. De Rob komt bijvoorbeeld net als de Denktank tot de aanbeveling dat er een verandering nodig is in de rol van de overheid, en vindt ook dat burgers en hun sociale verbanden meer verantwoordelijkheid en zeggenschap moeten krijgen en niet gereduceerd moeten worden 'tot uitvoeringsinstanties die de orders vanuit het gemeentehuis moeten uitvoeren'. Maar de Raad spreekt in dit verband ook van een paradigmashift die nodig is, en introduceert daarvoor een trap van overheidsparticipatie bestaande uit vijf treden: loslaten, faciliteren, stimuleren, regisseren, reguleren. Per situatie en onderwerp kan worden vastgesteld en toegelicht welke rol politiek en bestuur voor de overheid zien weggelegd. Met zo'n advies rijst onmiddellijk de vraag of met een dergelijk 'meetinstrument' niet juist veel meer de standaardisatiedrift van de toch al als inflexibel en bureaucratisch te boek staande lokale overheden wordt aangewakkerd. Waarom dan niet eens kijken in hoeverre het werken met participatieladders ook daadwerkelijk hout snijdt voor die lokale overheden bij het zoeken naar passende verhoudingen met maatschappelijke initiatieven?

Ook andere kansen om actuele inzichten van anderen te verweven met het verhaal worden node gemist. We noemen hier enkele voorbeelden van essentiële elementen uit het betoog.

Eerste voorbeeld: de netwerksamenleving. Van Gijzel zegt daarover in het voorwoord onder meer: '(...) de manier waarop wij onze samenleving hebben georganiseerd is aan verandering onderhevig. De verticale lijn, ons democratische bestel van Thorbecke, blijkt steeds vaker haaks te staan op de horizontale netwerksamenleving zoals Castells die beschrijft. (...) Twee werelden die samen moeten gaan, 'Living apart together: Thorbecke en Castells', zou je kunnen zeggen. Waarin wij als lokale overheid, als eerste overheid, ons moeten heroriënteren' (Denktank VNG, 2013, p. 3). Dat is een interessante invalshoek, ook vanuit de bestuurskunde en de beleidswetenschap, die helaas niet daadwerkelijk wordt opgepakt. Castells heeft echter recent gepubliceerd over de opkomst van maatschappelijke initiatieven en daar ook voor (de heroriëntatie van) Nederlandse gemeenten interessante bevindingen van onderzoek en inzichten over te melden (Castells, 2012; Castells, Caraca, \& Cardoso, 2012).

Ander voorbeeld: improvisatie. Dat is een van de kernelementen van de Denktank, de veranderende lokale samenleving die een improviserende gemeente vergt. Hans Boutellier (2011) schreef een diepgravende studie over de improvisatiemaatschappij, waarin hij vanuit verschillende theoretische en empirische invalshoeken recente maatschappelijke ontwikkelingen analyseert. Dat doet hij onder meer uitgebreid vanuit de netwerksamenleving zoals Castells die beschrijft. Die studie wordt echter niet genoemd en is ook niet benut.

Laatste voorbeeld: leren. Op enkele plaatsen in het rapport wordt gewezen op de noodzaak om van ervaringen (bijvoorbeeld in het omgaan met burgerinitiatieven) te leren. Als iets duidelijk wordt uit het rapport en recent onderzoek op het terrein van burgerinitiatieven, dan is dat wel dat momenteel niet alleen veel 
gemeenten experimenteren met de ondersteuning van burgerinitiatieven, maar ook worstelen met de vraag hoe al deze relevante ervaringen kunnen worden vastgehouden en in toekomstige gevallen kunnen worden benut. Ook op dit belangrijke punt wordt geen gebruik gemaakt van eerdere literatuur, bijvoorbeeld van de WRR, die herhaaldelijk over de lerende overheid heeft geschreven (WRR, 2006; 2012b) of, in het verlengde hiervan, over actuele concepten van leren in relatie tot sociaal ondernemerschap (Walraven, 2013).

\section{Improviseren als kernkwaliteit}

Het essayistische vertoog van de Denktank mondt uit in een pleidooi aan gemeenten om op een andere manier te gaan werken dan tot nu toe gebruikelijk was. Dit pleidooi gaat vergezeld van een agenda voor de VNG die in het rapport wordt afgebeeld als een briefje met zeven stellingen dat op een prikbord is geprikt. Kern van die agenda is de stelling dat maatschappelijke initiatieven vaker aanleiding voor experimenten zouden moeten zijn, waarbij de gemeenten hun vermogen tot improviseren versterken. Dit improviserend vermogen moet, zoals gezegd, tot in de haarvaten van de bestuurlijke organisatie doordringen. Daartoe zal er binnen de gemeentelijke organisatie niet alleen meer ruimte voor experimenten moeten komen, maar zal ook de tolerantie voor mislukkingen omhoog moeten.

Het is echter zeer onwaarschijnlijk dat dit kattebelletje ook maar ergens aan een gemeentelijk prikbord zal komen te hangen. Daartoe is de aanbeveling om meer te experimenteren en het improviserend vermogen te versterken immers bij lange na niet concreet genoeg. De gelijkenis dringt zich hier al snel op met de roep om tot meer maatschappelijke veerkracht te komen met het oog op de vele gevaren die ons boven het hoofd lijken te hangen in de huidige risicosamenleving. Zo stellen Arjen Boin en Michel Van Eeten vast in een achtergrondstudie over veerkracht, dat 'de gloedvolle betogen van politici en beleidsmakers vaak ten onrechte suggereren dat veerkracht een keuze is, (...) maar dat veerkracht net als liefde, vertrouwen en spontaniteit niet kan worden afgedwongen. Voor zover er dus kan worden "gestuurd" op veerkracht gaat het vooral om indirecte sturing: het creëren van de voorwaarden waaronder de kans groter wordt dat veerkracht zal ontstaan' (Boin \& Van Eeten, 2011, p. 46). Hetzelfde kan worden gezegd over de oproep aan gemeenten om maar te gaan improviseren. Het is per definitie lastig voor gemeenten om te anticiperen op maatschappelijke initiatieven omdat het hier steeds om doelstellingen, activiteiten en arrangementen gaat die in de samenleving zijn ontstaan. Gemeenten zullen dus intuïtief wel aanvoelen dat een zeker improvisatietalent noodzakelijk is, maar ook improviserend vermogen is geen capaciteit waar gemeenten alleen maar even aan herinnerd hoeven te worden. Waar dus indachtig de lijst met klassieke afweerreacties vooral behoefte aan lijkt te bestaan, is het verkrijgen van meer inzicht in de voorwaarden waaronder het improviserend vermogen van gemeentelijke overheden kan toenemen.

In een dergelijke analyse van het 'hoe' zal ook het probleem van de NPM-context waarin het 'meer experimenteren en meer improviseren' handen en voeten moet 
krijgen, serieus onder ogen moeten worden gezien. Juist in tijden van financiële crises en bezuinigingen moeten gemeenten het stellen met de realiteit dat met ieder nieuw incident waarbij sprake is van gemeenschapsgeld dat op een onrendabele of onoorbare wijze wordt besteed, de prestatiedruk en verantwoordingsdrift van hogerhand worden opgeschroefd. De Denktank heeft zich er wat dit betreft wel heel gemakkelijk vanaf gemaakt door die nadruk op meetbaarheid, prestaties en verantwoording bij de overheid af te doen als irrelevant zodra het om maatschappelijke initiatieven gaat.

Afgezien van 'praktische' problemen op het niveau van de uitvoering lijkt ook hier de vraag gerechtvaardigd of het pleidooi zelf voor 'improviseren in de lijn' wel op een juiste voorstelling van zaken is gestoeld. De veronderstelling van de Denktank dat gemeenten burgerinitiatieven tot nu toe bij voorkeur bij speciaal daartoe opgerichte afdelingen plegen te parkeren, is bijvoorbeeld in tegenspraak met de Twentse bevinding dat in Overijsselse gemeenten in veel gevallen de ondersteuning van de onderzochte initiatieven is ingebed in de wijkaanpak of het gebiedsgerichte beleid (Denters et al., 2013, p. 17). En ook voor de bevinding van de Denktank dat er sprake is van een groeiende verzameling van eigengereide burgers die bij het vormgeven van de publieke zaak steeds minder met de gevestigde instituties op hebben, kan geen steun worden gevonden in het Twentse onderzoek. Uit een in dit kader uitgevoerde enquête van het Overijsselse Burgerpanel blijkt niet alleen dat twee derde van de volwassen inwoners van Overijssel van mening is dat overheden burgerinitiatieven zo actief en ruim mogelijk moeten ondersteunen, en dat slechts vier procent vindt dat de overheden zich helemaal niet met burgerinitiatieven moeten bemoeien (ibid., p. 20), maar ook dat de tevredenheid van de respondenten over de gemeentelijke ondersteuning bovendien ongemeen groot was.

Daarmee is overigens niet gezegd dat in Overijssel die relatie tussen burger en overheid altijd geheel vlekkeloos verloopt. Als belangrijke knelpunten werden ook hier genoemd het gebrek aan flexibiliteit, verkokering ('van het kastje naar de muur'), de mate waarin gedane beloften worden nagekomen (ibid., p. 25) en het probleem dat de hulp die burgers krijgen niet altijd de hulp is die ze nodig hebben, hetgeen er volgens de onderzoekers op wijst dat er in nogal wat gevallen ook ondersteuning wordt geboden zonder dat burgers daar om hebben gevraagd (ibid., p. 33). Het overheersende beeld van initiatiefnemers van burgerinitiatieven dat zij zich graag gesteund weten door gemeentelijke overheden, staat echter lijnrecht tegenover dat van een door de Denktank opgeroepen 'weerbarstige burger'.

\section{De lat moet hoger}

De nieuwe VNG-denktank heeft per se geen dik rapport willen schrijven. Het was uitsluitend de bedoeling 'een aantal suggesties [te] doen' en nieuwe raadsleden en bestuurders die in het voorjaar 2014 zouden aantreden, 'stof tot nadenken' te bieden. 'Daarom acht de Denktank het niet nodig om de geselecteerde initiatieven tot in detail te analyseren. Wij concentreren ons op het presenteren van inzichten, reflecties en duidingen die we op basis van deze initiatieven hebben 
verzameld en die zowel voor de gemeenten als de VNG van betekenis lijken te zijn' (Denktank VNG, 2013, p. 25), schrijft Rob van Gijzel in zijn voorwoord. Maar dit is in al zijn eerlijkheid toch een opmerkelijke mededeling voor een nieuwe denktank. Die heeft nu aan 7 van de 300 via het internet verzamelde initiatieven een werkbezoek gebracht en op basis daarvan 'inzichten, reflecties en duidingen' verzameld die van betekenis 'lijken' te zijn, maar het vervolgens niet nodig gevonden die 'inzichten, reflecties en duidingen' 'tot in detail' te analyseren. De vraag hoe gemeenten daar concreet op in zouden moeten spelen, blijft onbeantwoord. Het rapport houdt zodoende op waar het belangrijk en nieuw had kunnen worden.

Met deze werkwijze wordt de lat duidelijk te laag gelegd. Mag je van een denktank niet ook verwachten dat kennis wordt genomen van de stand van onderzoek op dit terrein en dat mede op basis daarvan en op basis van de eigen ervaringskennis wordt gebrainstormd over de vraag hóé gemeenten de uitdagingen van burgerinitiatieven zouden kunnen oppakken? Die lat moet dus in een volgende exercitie een behoorlijk stuk hoger komen te liggen wil de Denktank tot de beeldbepalende praktijkgerichte kennisinstantie voor de lokale overheid uitgroeien die de naam 'Denktank' met een hoofdletter eer aan doet. Het rapport zelf genereert de nodige relevante vragen waar de Denktank direct mee aan de slag kan. Maar de centrale vraag die nu moet worden gesteld luidt: 'Oké, meer experimenteren en het improviserend vermogen versterken, maar hoe doen we dat?' Een gemeentelijke denktank die de tijd neemt om dit soort lastige vragen empirisch te verkennen en met wetenschappelijke inzichten te verbinden, zou een verrijking kunnen betekenen in het Nederlandse advieslandschap.

\section{Literatuur}

Boin, A., \& Eeten, M. van. (2011). Maatschappelijke veerkracht: een nieuw ideaal doorgrond, Achtergrondstudie. In RMO (2013), Terugtreden is vooruitzien. Maatschappelijke veerkracht in het publieke domein. Den Haag: Raad voor Maatschappelijke Ontwikkeling, 65-113.

Boutellier, H. (2011). De improvisatiemaatschappij. Over de sociale ordening van een onbegrensde wereld. Den Haag: Boom Lemma.

Castells, M. (2012). Networks of outrage and hope: Social movements in the internet age. Cambridge: Polity.

Castells, M., Caraca, J., \& Cardoso, G. (ed.). (2012). Aftermath: The cultures of the economic crisis. Oxford: Oxford University Press.

Denktank Vereniging van Nederlandse Gemeenten. (2013). Van eerste overheid naar eerst de burger. Over maatschappelijke initiatieven die de lokale overheid uitdagen. Den Haag: Vereniging van Nederlandse Gemeenten.

Denters, S.A.H., Bakker, J.H.M., Oude Vrielink, M.J., \& Boogers, M.R.G.J.A. (2013). Burgerinitiatieven in Overijssel. Een inventarisatie. Enschede: UTpublications.

Denters, S.A.H., Bakker, J.H.M., \& Klok, P.-J. (2011). Welke burger telt mee(r) in de doedemocratie? Beleid en Maatschappij, 38(4), 402-418.

Ministerie van Binnenlandse Zaken en Koninkrijksrelaties. (2013). De Doe-Democratie. Kabinetsnota ter stimulering van een vitale samenleving. www.rijksoverheid.nl. 
Raad voor de Maatschappelijke Ontwikkeling. (2013). Terugtreden is vooruitzien. Maatschappelijke veerkracht in het publieke domein. Den Haag: Raad voor Maatschappelijke Ontwikkeling.

Raad voor het Openbaar Bestuur. (2012). Loslaten in vertrouwen. Naar een nieuwe verhouding tussen overheid, markt én samenleving. Den Haag: Raad voor het openbaar bestuur.

Sociaal Cultureel Planbureau. (2012). Een beroep op de burger. Minder verzorgingsstaat, meer eigen verantwoordelijkheid? Sociaal en Cultureel Rapport 2012. Den Haag: Sociaal en Cultureel Planbureau.

Tonkens, E. (2010). De kwaliteit van burgerparticipatie in de stad: de casus bewonersbudgetten. Bestuurskunde, 19(4), 34-42.

Uitermark, J. (2014). Verlangen naar Wikitopia. Oratie Erasmus Universiteit Rotterdam.

Wetenschappelijke Raad voor het Regeringsbeleid. (2006). Lerende overheid. Een pleidooi voor probleemgerichte politiek. Amsterdam: Amsterdam University Press.

Wetenschappelijke Raad voor het Regeringsbeleid. (2012a). Vertrouwen in burgers. Amsterdam: Amsterdam University Press.

Wetenschappelijke Raad voor het Regeringsbeleid. (2012b). Publieke zaken in de marktsamenleving. Amsterdam: Amsterdam University Press.

Walraven, G. (2013). Een lerend perspectief op sociaal ondernemerschap. In E. Sterk, M. Specht \& G. Walraven (red.), Sociaal ondernemerschap in de participatiesamenleving. Van brave naar eigenwijze burger. Antwerpen/Apeldoorn: Garant, 168-189. 